\title{
Study on Mechanism of Influence of Mining Speed on Roof Movement Based on Microseismic Monitoring
}

\author{
Ke Ma $\mathbb{D}^{1,2}{ }^{1,2}$ Su-jian Wang, ${ }^{3}$ Fu-zhen Yuan, ${ }^{1,2,4}$ Yi-lin Peng, ${ }^{1,2}$ and Shi-min Jia ${ }^{4}$ \\ ${ }^{1}$ State Key Laboratory of Coastal and Offshore Engineering, Dalian University of Technology, Dalian, Liaoning 116024, China \\ ${ }^{2}$ Institute of Rock Instability and Seismicity Research, Dalian University of Technology, Dalian, Liaoning 116024, China \\ ${ }^{3}$ Shanxi Coal and Chemical Technology Institute Company Limited, Xi'an 710065, China \\ ${ }^{4}$ China Petroleum Pipeline Engineering Corporation, Langfang, Hebei 065000, China \\ Correspondence should be addressed to Ke Ma; mark1983@dlut.edu.cn
}

Received 21 June 2020; Revised 7 August 2020; Accepted 10 September 2020; Published 29 September 2020

Academic Editor: Fengqiang Gong

Copyright $\odot 2020 \mathrm{Ke} \mathrm{Ma}$ et al. This is an open access article distributed under the Creative Commons Attribution License, which permits unrestricted use, distribution, and reproduction in any medium, provided the original work is properly cited.

\begin{abstract}
Based on the study of the movement rule of the rock strata under the influence of the mining speed in the typical working face of Dongjiahe coal mine, the distribution of microseismic events and the variation characteristics of microseismic parameters in the slow and fast advancing stage are compared and analyzed, and the mechanism of the rock strata activity under the influence of the mining advancing speed is revealed from the perspective of the microfracture. The results show that the movement of the roof strata and the stress adjustment of surrounding rock have certain timeliness. The maximum advanced distance of microseismic events in the slow and fast stages is $185 \mathrm{~m}$ and $130 \mathrm{~m}$, respectively, and the maximum lag distance of microseismic events in the goaf is $120 \mathrm{~m}$ and $180 \mathrm{~m}$, respectively. The time of stress adjustment of surrounding rock is short, and the load transfer of the roof is insufficient. The advanced distance of microseismic events is increased, and the lag distance decreases. The percentage of microseismic events in the total number of events is $47 \%$ and $38 \%$, respectively, in the slow and fast stages of advancing. With the increase of mining speed, the intensity of roof strata activity in the goaf is weakened. The rock failure decreases and the volume of broken block increases, and roof collapse and rotary subsidence are insufficient. During the nonpressure period, the maximum development elevation of microseismic events is $+350 \mathrm{~m}$ and $+300 \mathrm{~m}$, respectively, in the slow and fast stages, while with the development elevation of microseismic events in the roof pressure near $+390 \mathrm{~m}$, increasing the mining speed cannot change the final failure height of the overburden. During the analysis period of roof pressure, the concentrated release of microseismic energy in the faster stage is $183 \%$ of that in the slower stage. The increase of large moment magnitude event frequency leads to the decrease of $b$ value. The risk of roof instability and strata behavior increases.
\end{abstract}

\section{Introduction}

Under the condition that the working face is safe and ventilation is permitted, changing the speed of pushing is an effective measure to increase the output rate of single working face. However, the development, expansion, and ultimate stability of surrounding rock fractures need some time $[1,2]$. The change of driving speed often leads to roof strata movement, and ore pressure appears abnormal, which has adverse effects on working face pressure and roadway support [3]. Therefore, it is of great significance to study the influence rule of pushing speed on the roof strata movement.
The change of mining speed has a direct impact on the subsidence and subsidence velocity of the main roof, resulting in the occurrence of rock pressure in the stope, causing the change of the surrounding rock stress environment. Liu et al. [4] proposed a comprehensive influence parameter of mining and geological induced ground fracture development to describe the effect of pushing rate on the development of surface cracks. The surface fissure angle and development cycle are linearly positively correlated and negatively correlated with the mining speed, respectively. Xie et al. [5] through numerical and similar material simulation analyzed the stress, displacement, and failure of fully mechanized caving face surrounding rock under different 
driving speeds in depth. Wang et al. [6] studied the influence mechanism of the fully mechanized caving working face mining speed on the stress and deformation of the surrounding rock. It is concluded that increasing the speed of advance, the front peak stress approaches the working face, and the peak stress increases. Zhang et al. [7], by means of laboratory test, numerical simulation, and on-site monitoring, obtained the safe driving speed of island working face under three hard conditions. Li et al. [8], based on the theory of the elastic foundation beam, analyzed the influence of the driving speed on the stress distribution of the advance support. The results show that the peak value of stress is directly proportional to the pushing speed, and the distance between the peak value and the coal wall is smaller.

The high speed propulsion of the working face will cause sudden change of roof subsidence velocity, resulting in the sudden increase in stress of surrounding rock. Combined with the occurrence characteristics of the coal seam, it is easy to induce rock burst, rib spalling of the coal wall, and advance instability. Feng et al. [9], based on the assumption of elastic foundation, established a model of the triangular supercharged loading cantilever beam. The analytical solution for the settlement, bending moment, and bending elastic energy density of the roof beam under the control of mining speed is derived. The analytical formula for the rotation angle, breaking span, and breaking release energy under the influence of mining speed is established. Wang and Wang [10] believed that the speed of advancing the working face improves the loading rate of the cantilever beam at the base roof. Due to the pseudoenhancement characteristics of the cantilever beam, the elastic strain energy increases, the ratio of the initial kinetic energy of the broken rock mass to the total strain energy increases, and the possibility of dynamic breaking and instability of the high strength mining face is increased. Zhao et al. [11] studied the relationship between the mining speed and the bending deformation energy of the roof. It is considered that the energy released from the roof increases exponentially with the increase of mining speed. Liu et al. [12], through cases analysis, found that high-speed mining and nonuniform mining are easy to induce rock burst.

The above research work adopts theoretical analysis and simulation tests to study the effect of pushing speed on roof rock activities and has achieved beneficial results for engineering sites. However, the mining site is complex and changeable. It is difficult to quantitatively evaluate the effect of pushing rate on roof activity and surrounding rock stress response in time [13]. Microseismic monitoring technology can capture the microcracks in the stope and delineate the surrounding rock damage area in real time [14-17]. The influence of driving speed on the stability of stope surrounding rock is evaluated.

In this paper, the microseismic monitoring system of a typical working face in a mine is constructed, and the change rule of the microfracture distribution in the stope under the influence of different pushing speed is analyzed. The influence characteristics of the pushing speed on the goaf roof activity are revealed. The stability of the surrounding rock of the working face is quantitatively evaluated through the variation of microseismic parameters. From the perspective of microfracture, the mechanism of the pushing rate affecting roof rock movement is analyzed, in order to provide certain references for the mine face pressure control and reasonable support under similar conditions.

\section{Geological Survey of Working Face}

The working face tends to be $1217 \mathrm{~m}$ long and tends to be $185 \mathrm{~m}$ wide. The coal seam no. 5 of Shanxi formation is mainly selected, the coal thickness is $2.5 \sim 4.1 \mathrm{~m}$, the average thickness is $3.3 \mathrm{~m}$, and there is a thin coal belt in the range of 540 765 $\mathrm{m}$ from the transportation lane. The coal thickness is $1.15 \sim 2.2 \mathrm{~m}$. The coal seam dip is about 3 degrees, which belongs to the nearly horizontal coal seam. The direct roof of the coal seam is dark-gray coarse sandstones with a thickness of $0.65 \sim 1.66 \mathrm{~m}$ and contains a small amount of muscovite. It contains pyrite nodules and a small number of plant fossils. The basic roof is gray medium and fine-grained sandstones with a thickness of $5.7 \sim 11.77 \mathrm{~m}$. The composition is mainly quartz, and the latter is dark rock debris. It contains more mica plates, mud siliceous cementation, and pyrite nodules. According to the positions of the key strata, the strata in the mining affected area are divided into direct roof, low rock group, middle rock group, and high rock group. According to the height data of the water flowing fracture zone and microseismic activity monitoring data of working face roof, only the low key stratum and middle key stratum of roof fracture and the high key stratum bend and sink. The progress of working face is shown in Table 1.

\section{Spatial-Temporal Evolution and Microfracture Mechanism of Microseismic Activity under the Influence of Mining Speed}

3.1. Construction of Microseismic Monitoring System. The advanced high-precision microseismic monitoring system produced from ESG Corporation, Canada, had been installed for working face used for the real-time monitoring, location, and analysis of microfracture of coal and rock mass. The system is mainly composed of microseismic sensors, Paladin mining data loggers, Hyperion ground data loggers, and $3 \mathrm{D}$ visualisation software based on the remote network transmission developed by Mechsoft Co. Ltd., Dalian, China. Microseismic sensors are geophones with a response frequency range of $15 \sim 1000 \mathrm{~Hz}$ and sensitivity of $43.3 \mathrm{~V}_{\mathrm{s} / \mathrm{m}}[18]$.

Combined with the mining and geological conditions of the working face, the geophones are arranged under the detection area track lane and the coal seam floor of the transport roadway, respectively, as shown in Figure 1. The bottom of the drill hole enters the bottom bedrock, the vertical depth is not less than $3 \mathrm{~m}$, and the vertical profile of the sensor layout is shown in Figure 1. During the installation of the sensors, the sensors are sent to the bottom of the drill hole and stuck firmly on the bottom rock wall with the installation tools. The moderate cement mortar is slowly injected into the drill hole so that the mortar can cover the sensor. When the mud starts to solidify, the installation tool 
TABLE 1: Some parts of advancing progress of working face \#22517.

\begin{tabular}{|c|c|}
\hline Time & Point distance $(\mathrm{m})$ \\
\hline 2015/01/09 & 981 \\
\hline 2015/01/19 & 942 \\
\hline $2015 / 01 / 30$ & 917 \\
\hline 2015/02/09 & 885 \\
\hline 2015/02/15 & 856 \\
\hline $2015 / 02 / 27$ & 847 \\
\hline 2015/03/09 & 803 \\
\hline 2015/03/19 & 779 \\
\hline $2015 / 03 / 30$ & 760 \\
\hline 2015/04/09 & 750 \\
\hline $2015 / 04 / 18$ & 745 \\
\hline $2015 / 04 / 29$ & 736 \\
\hline $2015 / 05 / 08$ & 730 \\
\hline 2015/05/19 & 720 \\
\hline $2015 / 05 / 30$ & 714 \\
\hline 2015/06/09 & 700 \\
\hline $2015 / 06 / 19$ & 694 \\
\hline $2015 / 06 / 29$ & 688 \\
\hline 2015/07/09 & 681 \\
\hline 2015/07/18 & 677 \\
\hline $2015 / 07 / 30$ & 665 \\
\hline 2015/08/08 & 648 \\
\hline 2015/08/19 & 642 \\
\hline $2015 / 08 / 30$ & 628 \\
\hline 2015/09/08 & 615 \\
\hline 2015/09/19 & 603 \\
\hline 2015/09/29 & 592 \\
\hline 2015/10/09 & 578 \\
\hline 2015/10/19 & 553 \\
\hline $2015 / 10 / 30$ & 530 \\
\hline 2015/11/09 & 514 \\
\hline 2015/11/18 & 499 \\
\hline $2015 / 11 / 29$ & 476 \\
\hline 2015/12/09 & 457 \\
\hline 2015/12/18 & 443 \\
\hline $2015 / 12 / 30$ & 426 \\
\hline 2016/01/08 & 410 \\
\hline 2016/01/18 & 397 \\
\hline 2016/01/30 & 379 \\
\hline 2016/02/05 & 369 \\
\hline 2016/02/18 & 357 \\
\hline $2016 / 02 / 28$ & 330 \\
\hline 2016/03/09 & 310 \\
\hline $2016 / 03 / 18$ & 300 \\
\hline $2016 / 03 / 29$ & 281 \\
\hline 2016/04/08 & 270 \\
\hline $2016 / 04 / 18$ & 257 \\
\hline
\end{tabular}

is slowly drawn out of the hole and the cement is used to fill the hole so that the sensor is fixed at the bottom of the drill hole [18].

To protect the goaf cable from casing and landfills and to ensure the signal transmission after the collapse of the mined out area, the sensors in the track lane and the transportation lane will transmit the signal through the cable to the workstations under the shaft, and the data collected by each sensor will be uploaded to the data processing server, the data storage, and the transmission server at the ground grouting station through the optical cable (via connection roadways). After being processed by field workers, they are sent to scientific research units and the party units. The topological structure of the microseismic monitoring system is shown in Figure 2 [18].

3.2. The Effect of Different Propulsion Speeds on the Distribution Characteristics of Microcracks. According to the advance progress of the working face, the average speed of mining in a period of time can be calculated. It can be found that maximum and minimum values of mining speed are $3.5 \mathrm{~m} / \mathrm{d}$ and $0.55 \mathrm{~m} / \mathrm{d}$, respectively. As the mining speed is $0.55 \mathrm{~m} / \mathrm{d}$, the coal mining technology is blasting mining and it coincides with the head-on meeting stage of coal mining and driving working face; similar working conditions cannot be found out; thus the subsmall mining speed value is chosen. Taking April 12, 2016, to April 16, 2016, as an example, the average daily recovery rate of the working face is $1.3 \mathrm{~m} / \mathrm{d}$, which is a relatively slow stage because the mining height has obvious influence on roof strata activity. Meanwhile, the stages of similar mining height and different mining speeds are selected for comparison. For example, from October 15, 2015, to October 30, 2015, the average daily recovery speed was $2.3 \mathrm{~m} / \mathrm{d}$, which was the relatively fast stage of advance. Figures 3(a) and 3(b) show the profile projection of the microseismic event distribution trend in the slow and rapid phase of the nonpressure generation period, respectively (two days). The results show that during the nonpressure period, the microseismic events are mainly concentrated around the mining face and the roof of the coal seam, forming a large microfracture area in the goaf and the advanced segment roof (i.e., the overlying strata failure area caused by mining). The microseismic events are mostly distributed in the front roof of the coal wall, while the number of microseismic events in the goaf is less. The number of microseismic events in the goaf in the slow and fast advancing stages accounted for $47 \%$ and $38 \%$ of total events, respectively. With the increase of the driving speed, the proportion of the microseismic events in the goaf area decreases gradually, which indicates that the roof rock failure and the intensity of activity decrease in the goaf area after increasing the daily pushing rate; the roof caving and rotary subsidence are insufficient at the moment. From the analysis of the vertical development height of the microseismic events, the height of the microseismic events developed is the largest near the working face and decreased gradually to the both sides. During the slow phase, the direct roof was fully collapsed and fracture developed in the roof strata. With the bending and subsidence of the key stratum, the upper soft rock has enough time for the failure of separation and fracture. The maximum development height of microseismic events is $+350 \mathrm{~m}$, and the high strata group occurs curve subsidence and separation failure, while the maximum development height of microseismic events is $+300 \mathrm{~m}$ at high speed. The distribution of microseismic events in the high strata group is basically absent. For the distribution of microseismic events in the goaf, the maximum development height of microseismic events in the goaf is distributed in the middle strata during the slow advancing 


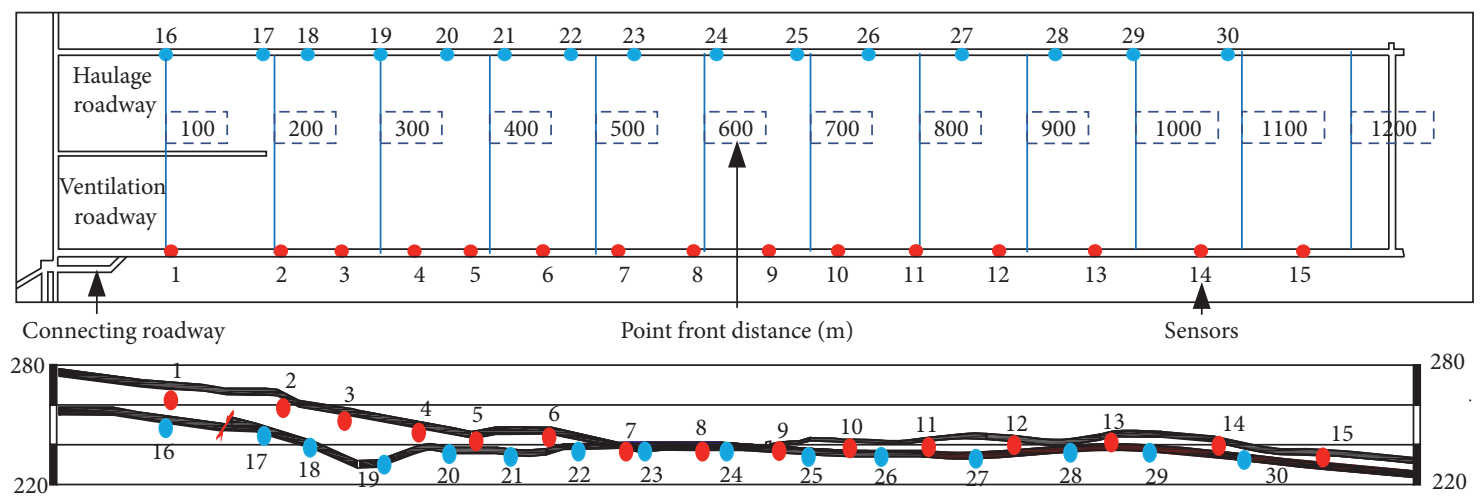

FIGURE 1: The flat profile projection of the working face sensor layout.

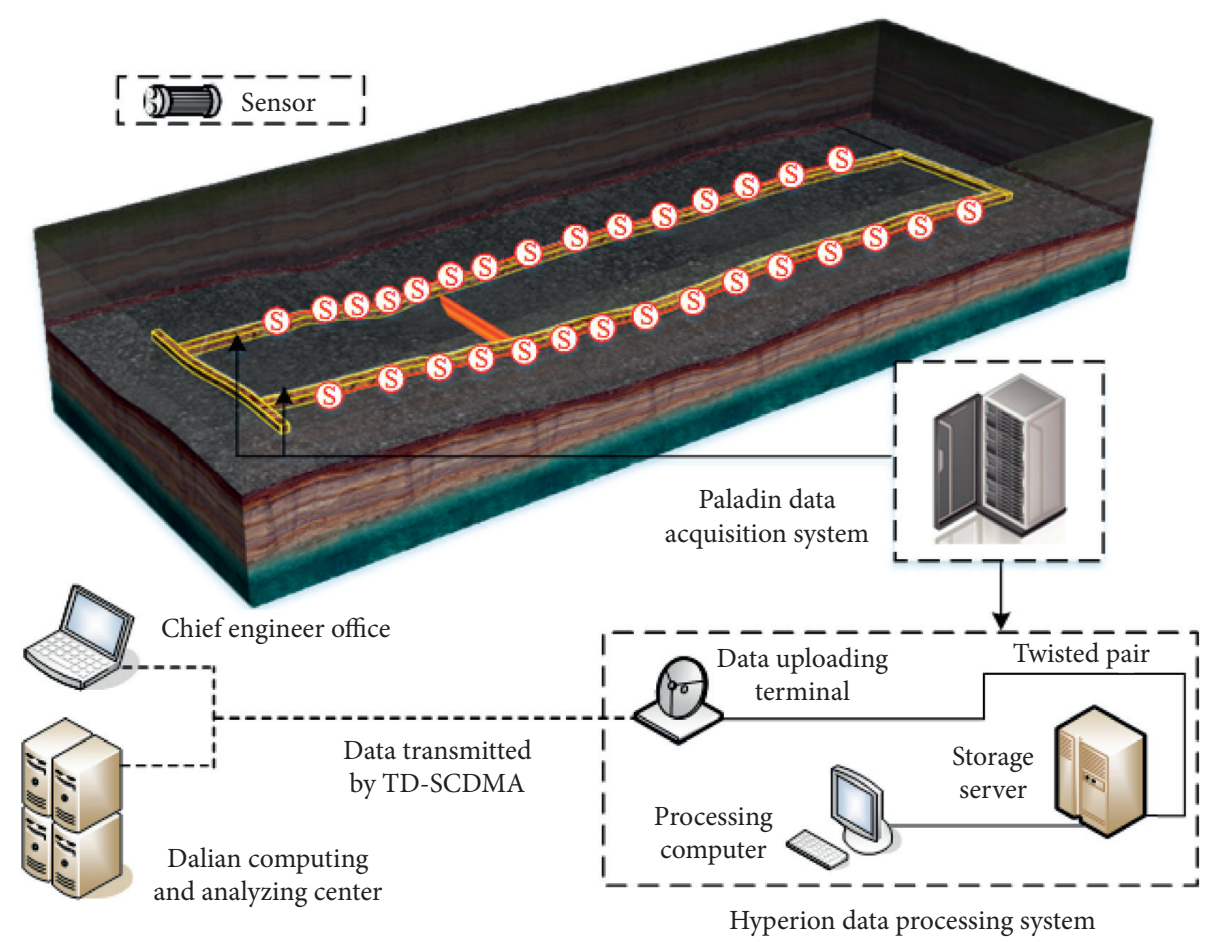

FIgURE 2: The topological structure of the microseismic monitoring system.

stage. However, in the fast advancing stage, except near the working face, the microseismic events in the goaf are mostly distributed in the immediate top and low rock group.

Figures 3(c) and 3(d), respectively, show the characteristics of the microseismic distribution of the overlying strata after a period of slower and faster speed considering the cyclic pressure. The results show that the maximum height of the microseismic events in the vertical direction is the top of the high rock group. It can be seen that changing the speed of pushing production cannot change the final development height of the overlying strata failure zone. By analyzing the characteristics of advance and lag distribution of microseismic events from the direction, it can be found that the maximum distance of the advance distribution of microseismic events in the slow and fast advancing stage is $185 \mathrm{~m}$ and $130 \mathrm{~m}$, respectively, and the maximum lag distance of the microseismic events in the goaf is $120 \mathrm{~m}$ and
$180 \mathrm{~m}$, respectively. It can be seen that the delayed development distance of the goaf microseismic events in the fast advancing stage is far greater than that in the slow advancing stage, which indicates that the advance speed changes have a significant impact on the timeliness of the goaf stability. In the slow mining advancing stage, the cracks in the overlying rock roof are developed and fully damaged, which leads to the faster time effectiveness of roof compaction in the goaf. However, in the fast mining advancing stage, the adjustment time of the surrounding rock stress is short, and the roof damage is not sufficient, and the goaf needs long time to reach the stable state of compaction. At the same time, when the advanced speed is slow, the fracture development of coal rock mass in front of the coal wall is affected by the advanced supporting stress for a long time, and the damage scope of the advanced segment coal seam and the surrounding rock of the roadway increases. 


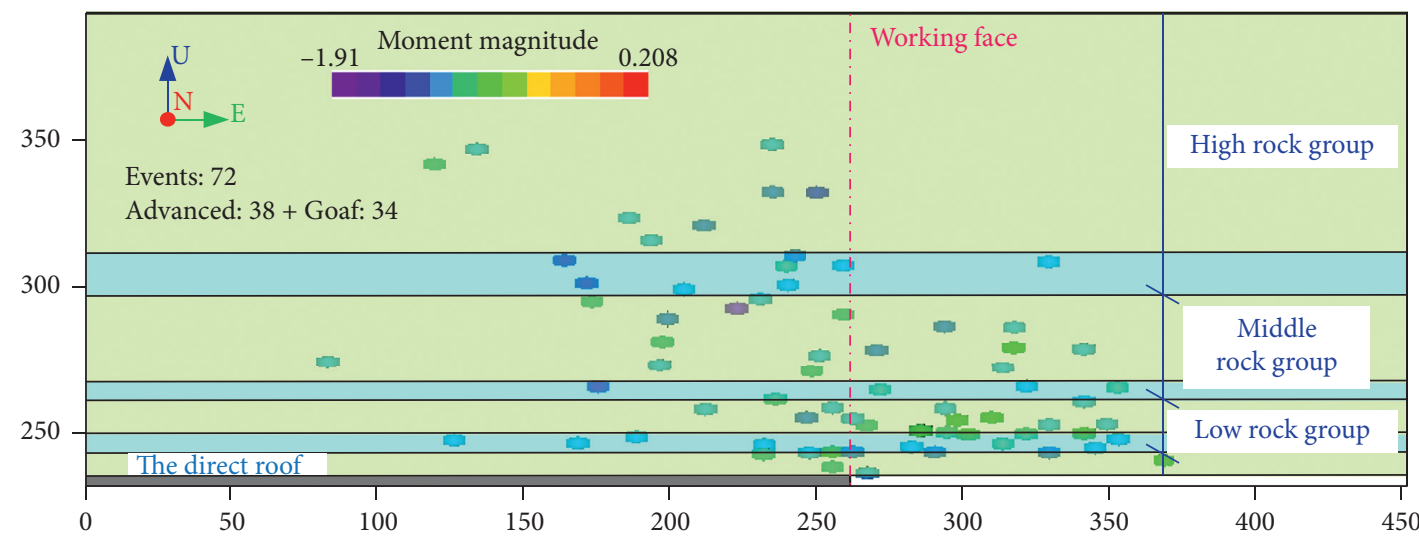

(a)

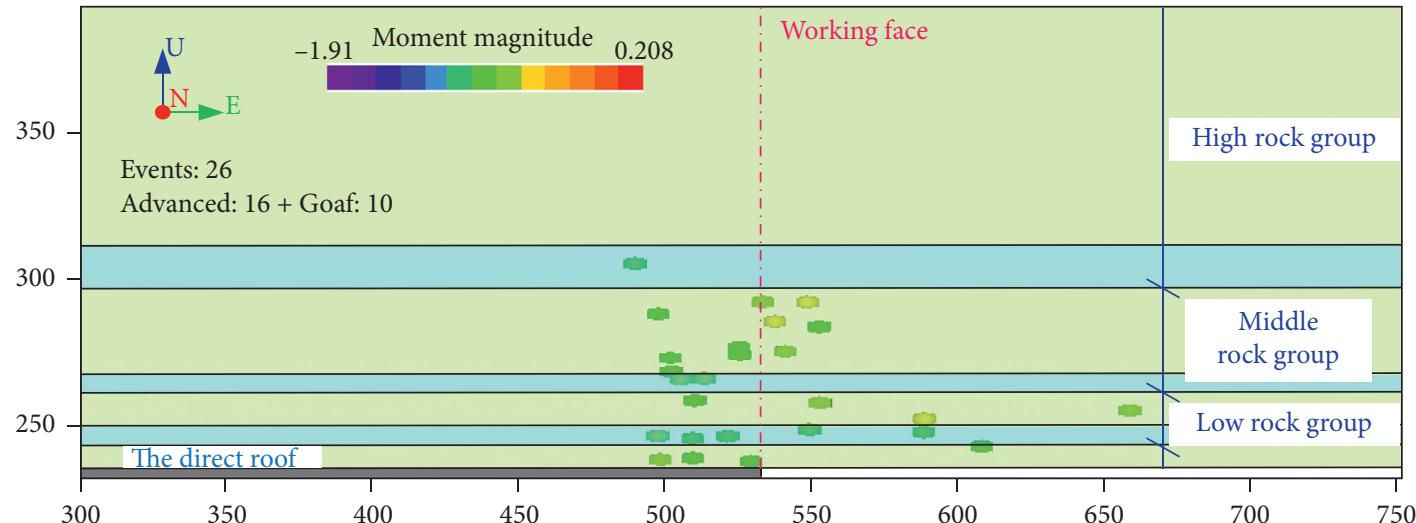

(b)

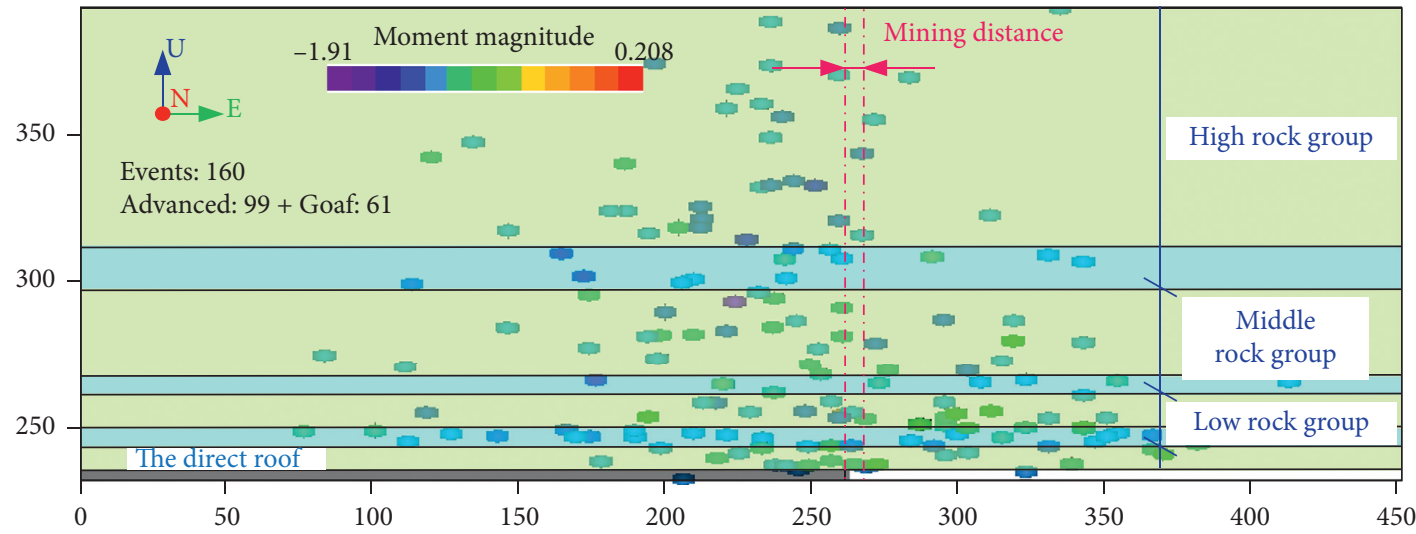

(c)

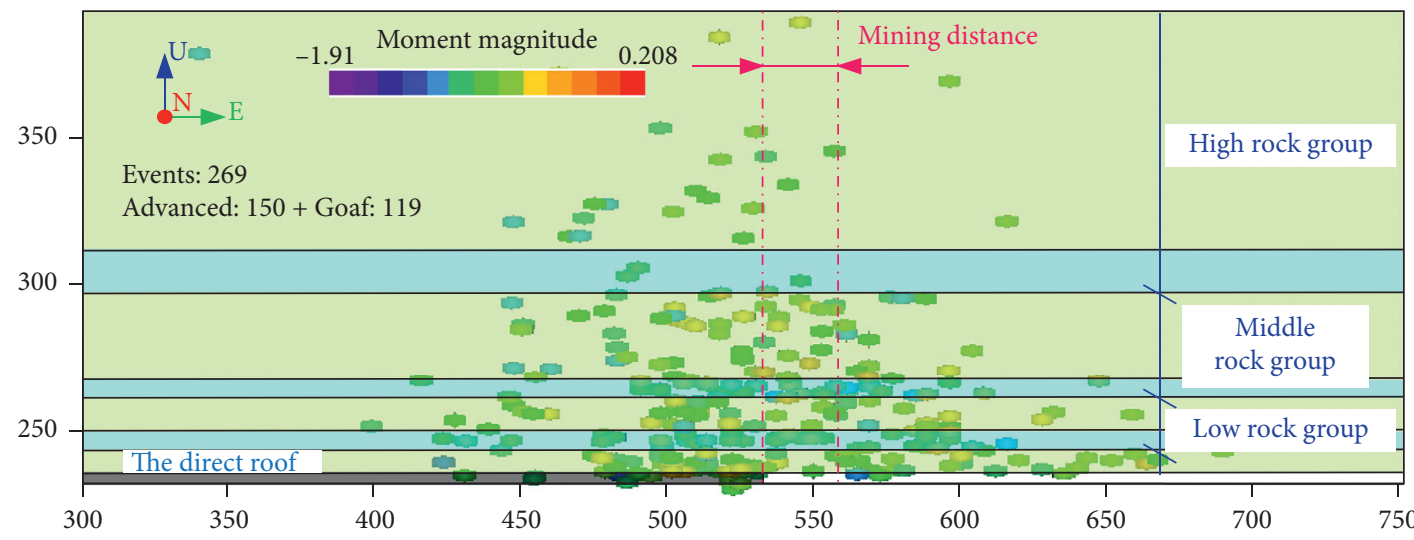

(d)

FiguRE 3: Characteristics of microseismic activity under different advancing speeds. (a) 2016.04.14 2016.04.15 (slow advancing). (b) 2015.10.30 2015.10.31 (fast advancing). (c) 2016.04.12 2016.04.15 (slow advancing). (d) 2015.10.15 2015.10.31 (fast advancing). 
Therefore, increasing the pushing rate can reduce the development height of the roof microseismic events during the nonpressure period. However, with the periodic breaking of the roof, the ultimate failure height of the overlying rock cannot be changed at last. Increasing the speed of mining in the production practice is conducive to reducing the mining pressure appearance (support pressure) of the working face properly during the nonpressurized period, but it does not change the final failure height of the overlying rock. It is impossible to change the development height of the roof fractured zone, and increasing the rate of mining cannot be used to prevent the roof from sudden (surge) water disasters. Besides, in the response of surrounding rocks, the advancing influence range of the working face can be effectively reduced by increasing the advancing speed, and the microseismic lag distance of the goaf can also be increased.

\subsection{Influence of Different Driving Speeds on Microseismic} Parameter Characteristics. After mining, the overlying strata movement and damage of surrounding rock are caused. A large number of microfracture events occur during the period. The daily construction and geological conditions are different. There are certain differences in the damage of surrounding rock, and the frequency and energy of microseismic events are also different. In order to investigate the number of microseismic events and change the trend of the energy released by the microseisms in the fast and slow advancing stage, taking into account the phenomenon of roof pressure, we selected the microseismic events from October 26, 2015, to October 29, 2015, and April 12, 2016, to April 15, 2016, as research objects.

As shown in Figure 4(a), within the monitoring area, the average daily occurrence of microseismic events in the slow and fast advancing stages during the nonpressurized period is 36 and 11 times each day, respectively. The number of microseismic events in the rapid phase is $31 \%$ of that in the slow phase. The microseismic events in the slow and fast advancing stages during the pressurized period are 51 and 28 times every day, respectively. That is to say, the number of microseismic events produced in the slow phase during the mining period is larger than that of the fast advancing stage. As shown in Figure 4(b), the average daily release of microseismic energy is $476 \mathrm{~J} / \mathrm{d}$ during the slow propulsion period of nonpressurized period, and the number of energy released per day is similar. The daily energy released by microseismic events in the fast advancing stage is unstable and smaller than that in the slow advancing stage; the cumulative release energy of microseismic in one cycle is slower than that in the slow advancing stage of propulsion. The concentrated release of microseismic energy in the fast advancing stage during the weighting period is $183 \%$ of that in the slow advancing stage.

Gutenberg and Richter [19], when studying the characteristics of seismicity, proposed the statistical relation between earthquake magnitude and frequency, that is the G- $\mathrm{R}$ relation [20]. Tang et al. [21], in the process of microseismic monitoring of a deep buried tunnel, found that the "moment magnitude-frequency" also obeys this basic rule:

$$
\log N=a-b M
$$

where $M$ is the magnitude of earthquake; $N$ is the earthquake frequency of magnitude $M+\Delta M$; " $a$ " value is the constant that represents the statistical time and the level of seismicity in the region; and " $b$ " value is the constant of magnitude distribution. It describes the relative values of small magnitude frequencies and large magnitude frequencies over a period of time. The relatively more the large magnitude events are, the gentler the curve is and the smaller the " $b$ " value is. Therefore, we can reflect the strength and stress of the material medium within the seismic range through the change of " $b$ " value. From the point of view of hypocenter activity characteristics, the $b$ value corresponding to the time of mine microseismic activity and fault slip is usually less than 0.8 , and the $b$ value of stress migration microseismic activity induced by mining activities is generally distributed between 1.2 and 1.5 [22]. The study shows that the microseismic activity area with large " $b$ " value is relatively less risky. The " $b$ " value is an important parameter for mine construction risk evaluation and reflecting the focal mechanism.

The distribution and frequency of the moment magnitude in the two stages of slow and fast progress are statistically analyzed. The fitting interval of moment magnitude is between the maximum and minimum moment magnitude, and the value of $\Delta M$ is 0.1 . As shown in Figure 5, the moment magnitude in the slow phase is mainly located between -1.5 and 0.8 , and a small number of events are located between -0.6 and 0.1 . The moment magnitude of the maximum frequency is -1.2 . In the fast advancing stage, moment magnitude is mainly between -1.0 and 0.3 , and the maximum frequencies of moment magnitude are -0.8 and -0.6 . The main distribution range and the maximum frequency of the moment magnitude in the fast advancing stage are both larger than those in the slow advancing stage. By the linear fitting of moment magnitude and frequency, the " $b$ " values of the slow and fast advancing stages are 0.9106 and 0.5599 , respectively. During the period, the roof strata experienced the breaking of the key strata and the large slip and subsidence of the roof after breaking. In this period, the microseismic activity is mainly composed of fault slip. The " $b$ " value of microseismic activity is smaller than that in the slow advancing stage when advancing at a fast advancing stage, which indicates that the larger scale microcracks occur at a fast advancing stage, the proportion is greater, the roof has a higher risk of instability, and mine pressure disaster accident is more likely to happen during the pressurized period.

Combined with single microseismic event moment magnitude and energy analysis, the moment magnitude and energy of a single microseismic event decrease in the slow advancing stage, and the roof overlying strata are in the process of slow deformation and fracture. The roof cracks develop and produce a large number of microfracture events. The concentrated strain energy is released by a large number of small energy events. The energy gathered in the surrounding rock of the roof and stope is fully released, and there are few large energy events. During the fast advancing stage, the moment magnitude and energy of the single microseismic event increase obviously, the roof activity is not sufficient, the 


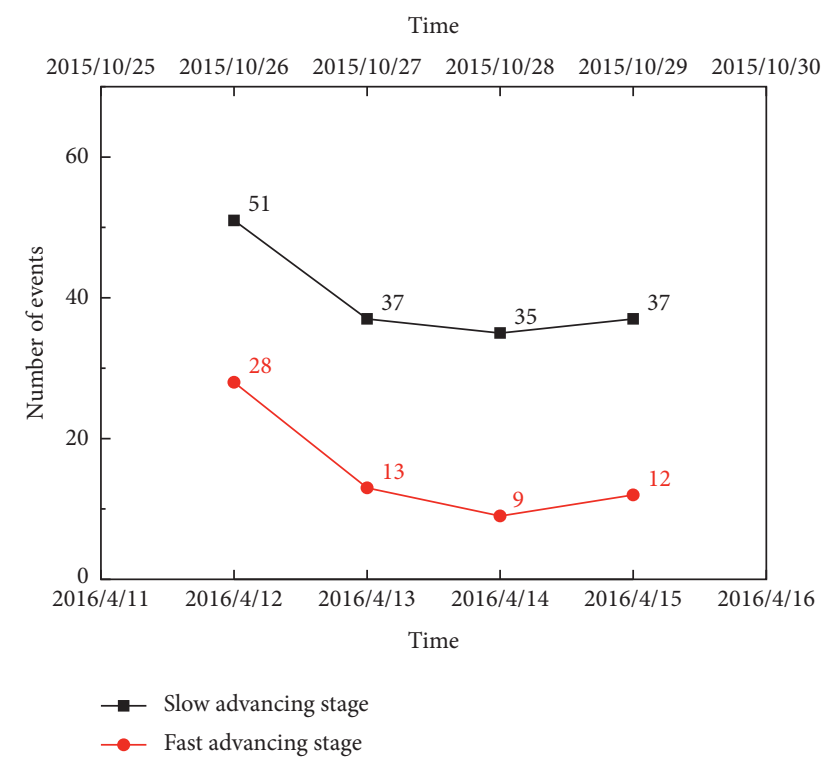

(a)

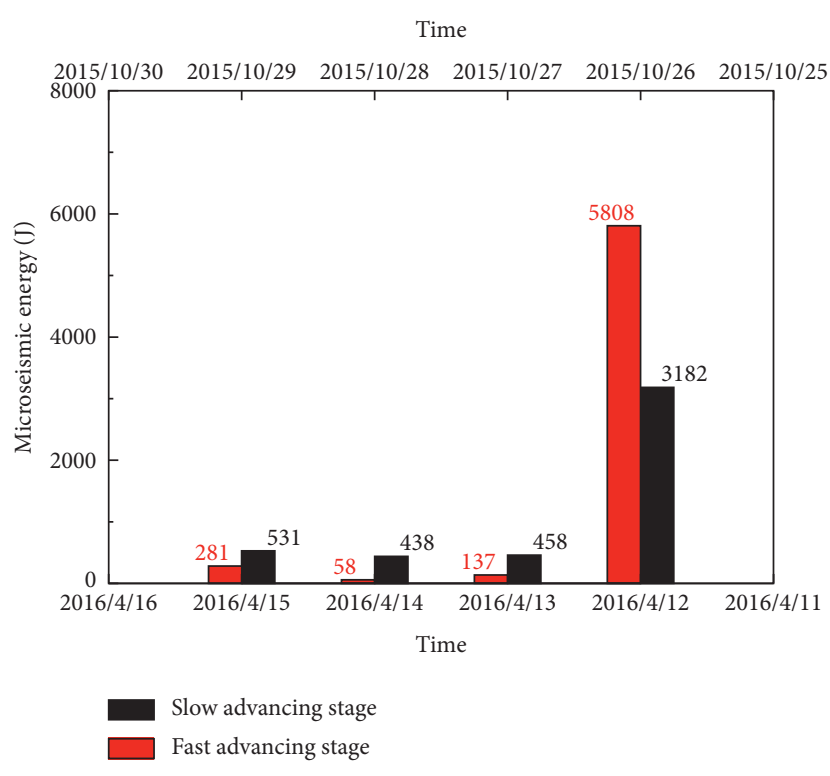

(b)

FIGURE 4: Variation of microseismic events and released energy under different mining speeds. (a) Variation of microseismic events under different mining speeds. (b) Variation of energy released by the microseisms under different mining speeds.

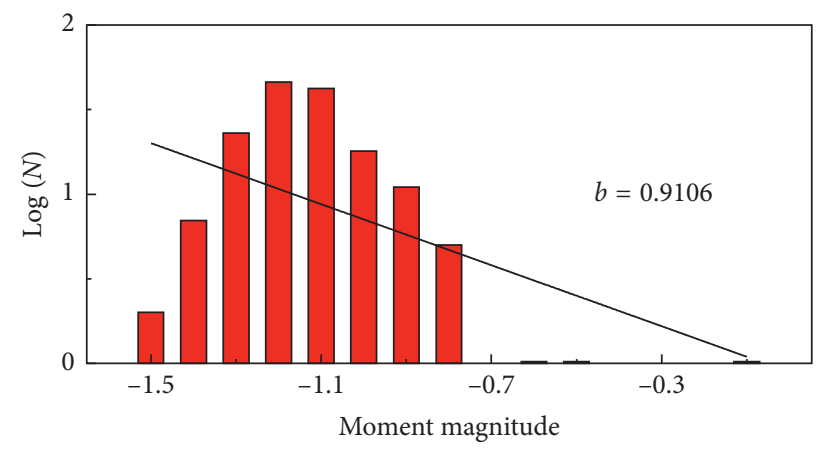

$\square \log (N)$
$\square$ Fitting curve

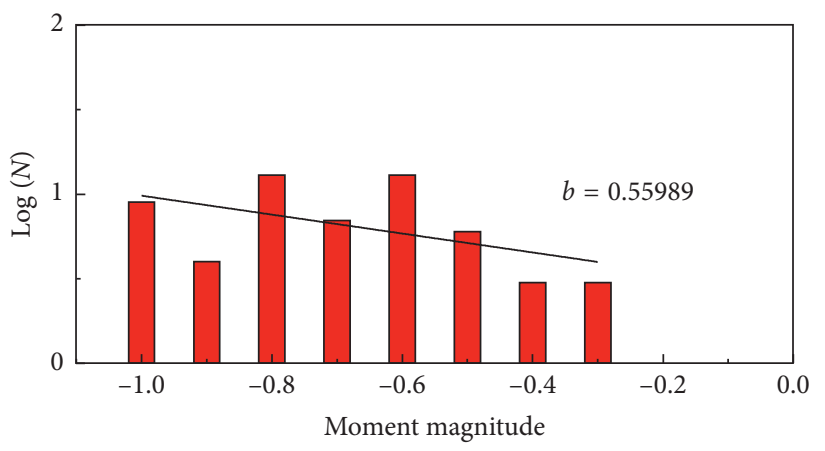

$\log (N)$ _ Fitting curve

FIGURE 5: Moment magnitude-frequency distribution of microseismic events at different advancing speeds. (a) Slow advancing stage. (b) Fast advancing stage.

number of microseismic events is less, and the concentrated strain energy is released by a small number of larger energy events. Most of the time, the energy is released in a single day and the accumulated energy is small, the energy release of the surrounding rock in the roof and stope is not enough, and the concentrated release of energy is easy to occur, which is not conducive to roof pressure control.

3.4. The Mechanism of Advancing Speed Based on Microseismic Monitoring. With the advance of long wall working face, the space formed after the coal mining is collapsed from the roof bottom to top, and bending and subsidence are filled and compacted. In this process, all the development, expansion, and ultimate stability of fractures need some time [23]. When the working face is advancing at a relatively fast advancing stage, the microseismic events in the stope decrease significantly and are mainly concentrated near the working face. At the same time, the proportion of the microseismic events in the goaf is reduced in the total number of events, the roof caving of the goaf is not enough, the vertical development height of the microseismic events is obviously reduced, the strata movement of the roof separation-breaking-rotation-subsidence and load transfer are not enough, and the stress of the surrounding rock of the stope is not adjusted adequately. The damage degree of deformation is reduced, and the internal crack is not developed. In addition, when the coal seam is lifted rapidly, the exposure space of the rock strata left behind after coal mining is increased, which further leads to the decrease of the goaf filling degree. After the low key stratum (basic roof) is broken, the revolving subsidence space is large, that is, $\Delta S_{2}$ in Figure 6(b) is larger than that in Figure 6(a) $\left(\Delta S_{1}\right)$. 


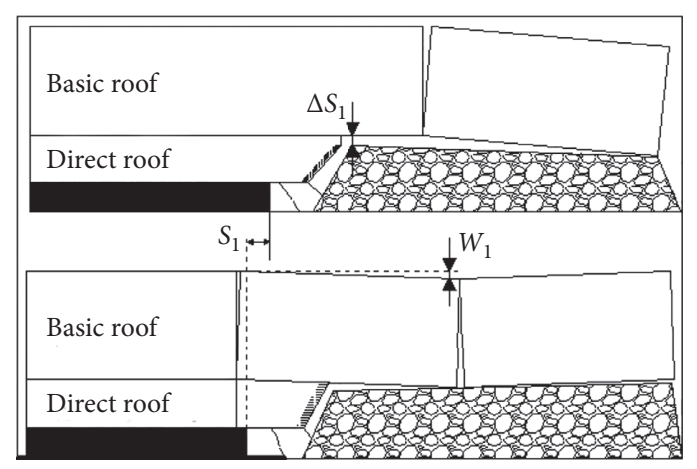

(a)

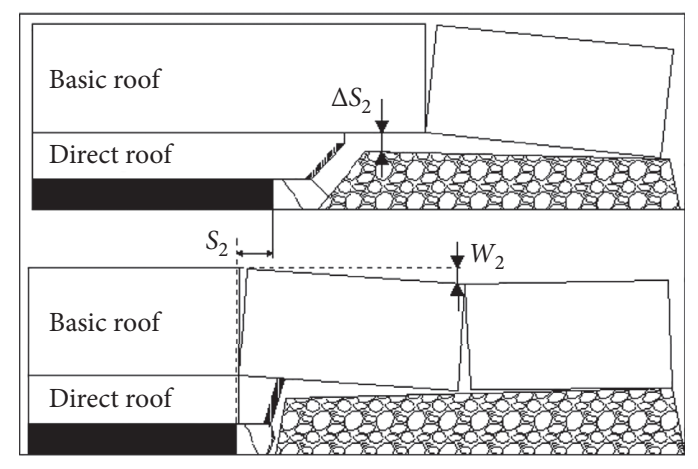

(b)

FIgURE 6: The rotation motion diagram of the basic top block under different propulsion speeds. (a) Slow advancing stage. (b) Fast advancing stage.

Analyzing from the aspect of the moment magnitude and energy of microseismic events, at the slow advancing stage of propulsion, a large number of small moment magnitude and small energy microseismic events occur on the roof. The daily microseismic accumulation and release energy are large, that is, the concentrated energy of the hard thick strata is fully released by a large number of small-scale and smallenergy microfractures, the energy released by daily microseismic accumulation is small at a fast advancing stage of propulsion, and a large amount of strain energy is accumulated in the hard thick strata.

In the fast advancing stage, with the roof low key stratum breaking, the critical block sinking amount $W_{2}$ (Figure 6(b)) is larger than $W_{1}$ (Figure 6(a)) when advancing slowly. After the critical stratum is broken, more slewing capacity is needed to reach the lower filling body so that the influence distance between the basic roof and the support will increase, resulting in the increase of the strength and persistence length of the cyclic pressurized period. Wang and Wang [10] proposed that when the working face propulsion is accelerated, it is found that the pseudo-reinforcement of the tensile strength of the basic roof strata leads to increase in the elastic strain energy stored in the cantilever beam before fracture and increases the probability of dynamic breaking instability of the basic roof during the fast advancing stage. At this time, the vertical development height of the microseismic events suddenly increases to the level of the final failure height of the overlying rock. Large-scale breakage or collapse occurred in the roof strata of the stope, and the cumulative energy of microseismic accumulation increased and is greater than that at the slow advancing stage. There were large energy events in single microseismic events. The frequency of microseismic events with larger moment magnitudes increased, and the " $b$ " value decreased; the risk of the roof instability and stope pressure development increases during the pressurized period.

\section{Conclusion}

Through the construction of the microseismic monitoring system in working face, the characteristics of roof movement and microfracture response of surrounding rock under the influence of mining speed are analyzed, the microseismic event distribution and microseismic parameter change rule under different mining speed and the focal mechanism reflected are analyzed, and the influence scope of mining and high-risk spatiotemporal distribution are delineated.

(1) During the nonpressure period, the proportion of microseismic events in the total number of events is $47 \%$ and $38 \%$, respectively, in the slow and fast stages of advance, and the maximum development elevation of microseismic events is $+350 \mathrm{~m}$ and $+300 \mathrm{~m}$, respectively. With the increase of push mining speed, the intensity of roof strata activity in goaf is weakened; the rock failure decreases and the volume of broken block increases; roof collapse and rotary subsidence are insufficient.

(2) With the periodic roof pressure, the maximum distance of microseismic events in the slow and fast stages is $185 \mathrm{~m}$ and $130 \mathrm{~m}$, respectively, and the maximum distance of microseismic events in the goaf is $120 \mathrm{~m}$ and $180 \mathrm{~m}$, respectively. The change of advance speed has a significant effect on the timeliness of goaf stability. The increase of advance speed has a short time for stress adjustment of surrounding rock and insufficient transmission of the roof load.

(3) In a period, the number of microseismic events in the fast advancing stage is $31 \%$ of that in the slow advancing stage, but the interval value of the moment magnitude and the maximum frequency moment magnitude of microseismic events increase, the frequency of the large moment magnitude events increases, the $b$ value decreases, and the concentrated release of microseismic energy in the fast advancing stage is $183 \%$ of that in the slow advancing stage. The roof instability and the mine pressure appearance in the stope increased the risk.

(4) With the increase of push mining speed, the rotation speed and subsidence of the key fast body after fracture increase, which leads to the increase of strength and duration of periodic weighting, the increase of elastic strain energy accumulated in the key strata, the increase of moment magnitude and energy of microseismic events, and the risk of instability of surrounding rock in the stope. 
(5) In rock mass engineering activities, excavation speed has a significant impact on the stability of surrounding rock. Through the parameters such as time-space distribution of microseismic events, moment magnitude, energy, and $b$ value, the microfracture information of surrounding rock under different excavation speeds is obtained, and the risk of rock mass instability is further evaluated.

\section{Data Availability}

The microseismic monitoring data used in this paper come from Dongjiahe Monitoring Group of Dalian University of Technology and Dalian Mechsoft Co. Ltd. So, they cannot be made freely available.

\section{Conflicts of Interest}

The authors declare that they have no conflicts of interest regarding the publication of this paper.

\section{Acknowledgments}

This research was supported by the National Key Research and Development Plan of China (grant no. 2017YFC1503103), the National Natural Science Foundation of China (grant nos. 51774064, 51974055, and 41941018), the Fundamental Research Funds for the Central Universities (grant no. DUT20GJ216), and the Special-Funded Program on National Key Scientific Instruments and Equipment Development (grant no. 51627804).

\section{References}

[1] L. Wang and G. Xie, "Influence of mining velocity on dynamic disasters in the coal and rock mass at a fully mecha-nized mining face," Journal of China University of Mining and Technology, vol. 39, no. 1, pp. 70-74, 2010.

[2] S. Wang, X. Li, and S. Wang, "Separation and fracturing in overlying strata disturbed by longwall mining in a mineral deposit seam," Engineering Geology, vol. 226, pp. 257-266, 2017.

[3] M. Qian, P. Shi, J. Xu et al., Mining Pressure and Strata Control, China University of Mining and Technology Press, Beijing, China, 2010.

[4] H. Liu, K. Deng, X. Zhu, and C. Jiang, "Effects of mining speed on the developmental features of mining-induced ground fissures," Bulletin of Engineering Geology and the Environment, vol. 78, no. 8, pp. 6297-6309, 2019.

[5] G. Xie, J. Chang, and X. Hua, "Influence of mining velocity on mechanical characteristics of surrounding rock in fully mechanized top-coal caving face," Chinese Journal of Geotechnical Engineering, vol. 29, no. 7, pp. 963-967, 2007.

[6] J. Wang, S. Jiao, and G. Xie, "Study on influence of mining rate on stress environment in surrounding rock of mecha-nized top caving mining face," Chinese Journal of Rock Mechanics and Engineering, vol. 25, no. 6, 7 pages, 2006.

[7] H. Zhang, Y. Li, Y. Chen et al., "Study on safety pushing forward speed of island coal mining face under hard roof and hard seam and hard floor conditions," Coal Science and Technology, vol. 45, no. 2, pp. 6-11, 2017.
[8] L. Li, X. He, Y.-q. Chen, Y.-c. Li, C.-h. Shi, and Y.-p. Zhu, "Influence of different propulsion speeds on the characteristics of mine pressure in the fully mechanized caving face during rotary stage," Geotechnical and Geological Engineering, vol. 37, no. 5, pp. 3937-3947, 2019.

[9] L. Feng, L. Dou, X. Wang et al., "Mechanism of mining advance speed on energy release from hard roof movement," Journal of China Coal Society, vol. 44, no. 11, pp. 3329-3339, 2019.

[10] J. Wang and Z. Wang, "Impact effect of dynamic load induced by roof in high-intensity mining face," Chinese Journal of Rock Mechanics and Engineering, vol. 34, no. S2, pp. 3987-3997, 2015.

[11] T. Zhao, W. Guo, F. Han et al., "Analysis on energy accumulation and release of roof under influence of mining speed," Coal Science and Technology, vol. 46, no. 10, pp. 37-44, 2018.

[12] J. Liu, H. Sun, Z. Tian et al., "Effect of advance speed on rock burst in coal mines and its dynamic control method," Journal of China Coal Society, vol. 43, no. 7, pp. 1858-1865, 2018.

[13] S. Wang, X. Li, J. Yao et al., "Experimental investigation of rock breakage by a conical pick and its application to nonexplosive mechanized mining in deep hard rock," International Journal of Rock Mechanics and Mining Sciences, vol. 122, Article ID 104063, 2019.

[14] T. Li, T. Mei, X. Sun, Y. Lv, J. Sheng, and M. Cai, "A study on a water-inrush incident at Laohutai coalmine," International Journal of Rock Mechanics and Mining Sciences, vol. 59, pp. 151-159, 2013.

[15] X. Liu, C. A. Tang, L. Li, P. Lv, and R. Sun, "Microseismic monitoring and stability analysis of the right bank slope at dagangshan hydropower station after the initial impoundment," International Journal of Rock Mechanics and Mining Sciences, vol. 108, pp. 128-141, 2018.

[16] C. A. Tang, J. Wang, and J. Zhang, "Preliminary engineering application of microseismic monitoring technique to rockburst prediction in tunneling of jinping II project," Journal of Rock Mechanics and Geotechnical Engineering, vol. 2, no. 3, pp. 193-208, 2010

[17] J.-R. Zhou, T.-H. Yang, P.-H. Zhang, T. Xu, and J. Wei, "Formation process and mechanism of seepage channels around grout curtain from microseismic monitoring: a case study of zhangmatun iron mine, China," Engineering Geology, vol. 226, pp. 301-315, 2017.

[18] F. Yuan, K. Ma, D. Zhuang et al., "Preparation mechanism of water inrush channels in bottom floor of dongjiahe coal mine based on microseismic monitoring," Journal of China Coal Society, vol. 44, no. 6, pp. 1846-1856, 2019.

[19] B. Gutenberg and C. F. Richter, "Frequency of earthquakes in California," Bulletin of the Seismological Society of America, vol. 34, no. 4, pp. 185-188, 1944.

[20] N. Xu, F. Dai, Z. Zhou et al., "Study of characteristics of b value for microseismic events in high rock slope," Chinese Journal of Rock Mechanics and Engineering, vol. 33, no. S1, pp. 3368-3374, 2014.

[21] Z. Tang, X. Liu, C. Li et al., "Microseismic characteristic analysis in deep TBM construction tunnels," Journal of Tsinghua University (Science and Technology), vol. 58, no. 5, pp. 461-468, 2018.

[22] M. R. Hudyma, D. Milne, and D. R. Grant, Geomechanics of Sill Pillar Mining in Rockburst Prone Conditions: Final Report: Sill Pillar Monitoring Using Conventional Methods, Mining Research Directorate, Ontario, Canada, 1995.

[23] X. Wang, J. Xu, W. Zhu et al., "Influence of high mining velocity on periodic weighting during fully-mechanized mining in a shallow seam," Journal of China University of Mining and Technology, vol. 41, no. 3, pp. 349-354, 2012. 